\title{
Quick overview of diagnostic kits and smartphone apps for urologists during the COVID-19 pandemic: a narrative review
}

\author{
Hyusim Park ${ }^{1}$, Peng Jin ${ }^{2,3}$, Sungyong Jung ${ }^{1}$, Jayoung Kim ${ }^{2,4,5}$ \\ ${ }^{1}$ Department of Electrical Engineering, University of Texas at Arlington, Arlington, TX, USA; ${ }^{2}$ Departments of Surgery and Biomedical Sciences, \\ Cedars-Sinai Medical Center, Los Angeles, CA, USA; ${ }^{3}$ Shengjing Hospital of China Medical University, Shenyang, Liaoning, China; ${ }^{4}$ Departments \\ of Surgery and Biomedical Sciences, Cedars-Sinai Medical Center, Los Angeles, CA, USA; ${ }^{5}$ Department of Medicine, University of California Los \\ Angeles, CA, USA \\ Contributions: (I) Conception and design: J Kim; (II) Administrative support: J Kim, S Jung; (III) Provision of study materials or patients: None; (IV) \\ Collection and assembly of data: H Park, P Jin; (V) Data analysis and interpretation: H Park, P Jin; (VI) Manuscript writing: All authors; (VII) Final \\ approval of manuscript: All authors. \\ Correspondence to: Jayoung Kim, PhD. Departments of Surgery and Biomedical Sciences, Cedars-Sinai Medical Center, Davis 5071, 8700 Beverly \\ Blvd., Los Angeles, CA 90048, USA. Email: Jayoung.kim@csmc.edu.
}

\begin{abstract}
The COVID-19 pandemic was an unprecedented event that has caused incredible challenges in all areas of society. However, unlike previous global pandemics, modern advancements in technology and medicine have made it possible to respond much more rapidly. Within months, countries around the world developed diagnostic kits and smartphone applications to tackle the virus. Many of these diagnostic kits vary in what they target and have different uses. Smartphone applications have been developed to provide real-time information to users regarding potential exposure, statistics, updated news, etc. Depending on the country, resources and government policies have created a wide range of products and applications. This narrative review paper focuses on providing a general overview of diagnostic kits and smartphone applications in three major countries, the U.S., South Korea, and China. Smartphone applications were used for tracing person-to-person contact and preventing the spread of COVID-19. These tools allowed public health officials to quickly identify people who may have had exposure to COVID-19 and allows them to act accordingly. In addition to discussing the mechanisms behind diagnostic kits, topics in legislation and policy for contact tracing will also be discussed. As nations enter into the next phase of the pandemic, there are serious considerations to be made about how technology can be integrated into handling future healthcare crises.
\end{abstract}

Keywords: COVID-19; urologists; diagnostic kits; smartphone applications

Submitted Jun 29, 2020. Accepted for publication Nov 12, 2020.

doi: $10.21037 /$ tau-20-1042

View this article at: http://dx.doi.org/10.21037/tau-20-1042

\section{Introduction}

On March 11, 2020, severe acute respiratory syndromecoronavirus-2 (SARS-Cov-2), which causes the COVID-19 infection, was officially declared as a pandemic by the World Health Organization (WHO). As of June 1, 2020, more than 6.26 million people have been infected and more than 380,000 lives have been lost worldwide. The mortality rate of COVID-19 differs across countries, possibly due to differences in testing capacity, demographics, and other factors (1). Because COVID-19 can spread through asymptomatic patients, the number of confirmed cases is also in continual flux (2).

The U.S. reported its first confirmed COVID-19 case in the state of Washington. This individual had previously traveled to Wuhan, China in early January 2020 (3). Gradual increases in confirmed cases slowly rose in the U.S., 


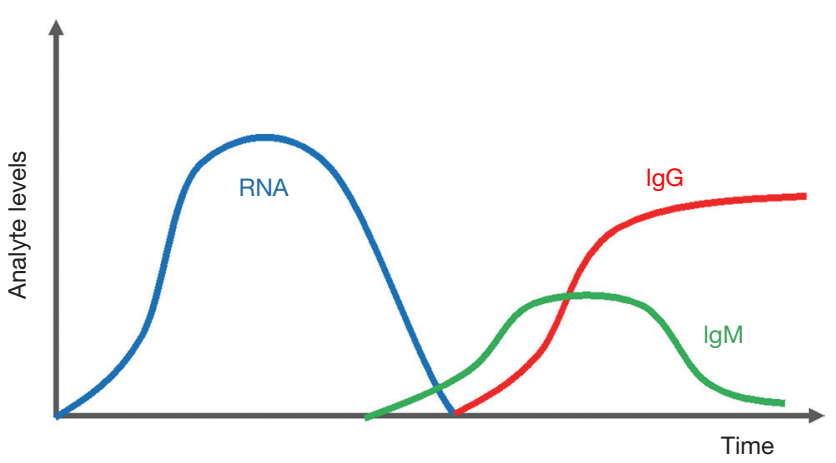

Figure 1 Changes in analyte levels following COVID-19 infection. Infection with SARS-CoV-2 leads to a building increase in viral mRNA, which peaks around 5-7 days after infection. This mRNA load begins to decrease after but is detectable up until day 14. As the viral mRNA starts to taper off, the patient's body begins to produce antibodies against the virus. The IgM antibody starts to build 5 days after the onset of symptoms and peaks around 9 days after infection. The IgG antibody is produced 14 days after infection and continues to build for a prolonged period of time, approximately 35 days. SARS-CoV-2, severe acute respiratory syndrome-coronavirus- 2 .

with the first COVID-19 death reported on February 29, 2020. Even with efforts to reduce spread, such as closing schools and preventing gatherings, the U.S. eventually had the most confirmed cases of COVID-19 globally, with 140,000 in March 29, 2020 (4). As of June 1, 2020, there are more than 1.79 million confirmed cases in the U.S., which accounts for almost a third of cases worldwide (5).

Fortunately, although there are consistently newly confirmed cases daily, the rate appears to be declining in some parts of the U.S. (5) However, most public health experts anticipate a second wave in the fall of 2020 (6-8). Since there are currently no effective therapies or vaccines available, the only way to prevent or mitigate a second wave is to take necessary precautions, such as social distancing and frequent hand-washing (9). The goal of this review paper is to provide an overview of trending diagnostic kits and smartphone applications against COVID-19. To this end, we searched databases and literatures available using keywords such as COVID-19, diagnostic kits, and smartphone applications. This narrative review article will summarize presently available methods for mitigating spread. Since South Korea is an established outstanding example of a country managing the COVID-19 pandemic well, the diagnostic kits and applications being widely used in that country will also be discussed.
The authors present the following article in accordance with the Narrative Review reporting checklist (available at http://dx.doi.org/10.21037/tau-20-1042).

\section{COVID-19 diagnostic tests}

To cope with the COVID-19 pandemic, diagnostic test kits are being evolved rapidly all over the world. Diagnostic tests can be categorized based on the analytes being measured, such as molecules or antibody. A molecular test detects certain genes, proteins, or molecules in a sample while an antibody test searches for virus-matched antibodies in the blood.

In relation to COVID-19, most molecular diagnostic tests look for the COVID-19 N gene or RdRP gene; whereas diagnostic antibody tests look for IgG or IgM antibodies (10-13). Figure 1 shows the levels of analytes over time in samples from COVID-19-positive patients after infection. Once SARS-CoV-2 enters the human body, only the viral ribonucleic acid (RNA) can be detected for the first several days after infection. The viral load continues to increase until day 5 or 6 . Around day 7, the viral RNA load starts to decrease; however, detection can be done until day 13 or 14 (14). The IgM antibody response is normally elicited 5 days after the initial onset of symptoms and hits peak levels around day 9. It is detectable until days 14-21. The IgG antibody rises after 14 days and generally peaks around or after clinical recovery, which 28-35 days after infection $(15,16)$.

Based on the characteristics of the detected target, different COVID-19 tests kits have optimal periods of use. Molecular tests, which detect viral RNA directly, can diagnose COVID-19 within the early stages of the disease, before symptoms and antibodies form; thereby, making it ideal as a primary diagnostic tool $(17,18)$. On the other hand, antibody tests can be used as a subsidiary diagnostic tool and is ideal for research purposes; it can be used to track potential asymptomatic patients and discover new findings behind immunity against SARS-CoV-2 (19). Diagnostic tests start with the collection of samples, such as blood or swabs collected from the throat. The presence of target analytes is then tested for in the samples and attained data is analyzed to determine whether or not the person is positive for COVID-19.

\section{Molecular test}

Molecular diagnostic tests usually utilize reverse transcription 

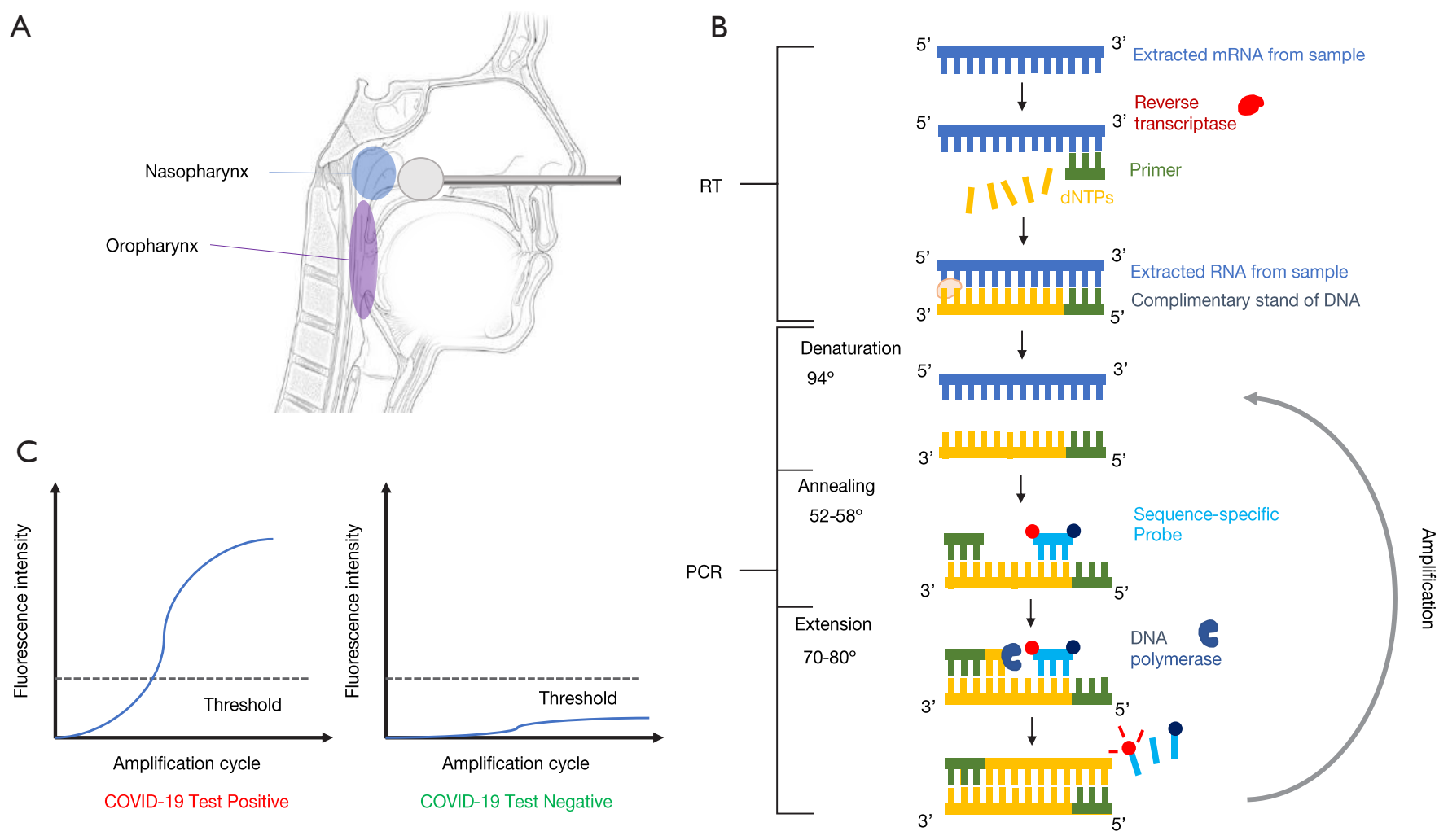

Figure 2 Example workflow for a one-step RT-PCR COVID-19 diagnostic test. (A) Collection of the sample from either the nasopharynx (upper respiratory) or oropharynx (lower respiratory) using a cotton swab. (B) Overview of RT-PCR. The mRNA is extracted from the sample and a primer attaches to the sequence of interest with reverse transcriptase. Sequence-specific probes that are conjugated with either fluorescence or color attaches and this process is amplified, leading to a detectable signal. (C) Analysis of results. A threshold for the signal intensity is established and if the fluorescence passes that threshold, then the patient is considered positive for COVID-19. RT-PCR, reverse transcription polymerase chain reaction.

polymerase chain reaction (RT-PCR) or reverse transcription loop-mediated isothermal amplification (RT-LAMP). RTPCR takes around 90-120 minutes to complete, while RTLAMP can be done in 30 minutes. Successful detection of SARS-CoV-2 in these two methods depends on the design of primers that bind specifically to the viral RNA and its fragments. Most molecular diagnostic tests for COVID-19 use the RT-PCR technique. Figure 2 shows an example workflow for a RT-PCR COVID-19 diagnostic test. The first step involves collecting sputum or bronchial fluid samples from the upper or lower respiratory tract (Figure 2A). Upper respiratory sources are preferred due to its ease. As of April 29, 2020, the Centers for Disease Control and Prevention (CDC) recommends collecting samples from the nasopharynx (NP) rather than the oropharynx (OP) (20). It is extremely important to collect samples as instructed by trained professionals in order to avoid false results (21).

With the collected sample, RNA is extracted using guanidinium thiocyanate-phenol-chloroform. After extraction, the sample is ready for RT-PCR, which detects specific SARS-CoV-2 mRNA (Figure 2B). RT synthesizes complementary deoxyribonucleic acid (cDNA) from RNA, while PCR amplifies the target cDNA. RT must be performed together (one-step) or before (two-step) PCR. From the amplification process, a fluorescent signal is emitted from sequence-specific probes or fluorescent dye, which can then be quantified using electronics or the naked eye. RT-PCR is the gold standard for detecting COVID-19 due to its high accuracy. However, the sensitivity of kits varies depending on the manufacturer and instruments used. Low sensitivity can lead to false negatives. 
Additionally, training must be given in order to ensure that samples are collected and processed properly, which can make RT-PCR very labor-intensive. Furthermore, RT-PCR requires expensive equipment for proper processing $(22,23)$ (Figure 2C).

\section{Antibody test}

Also known as a serological test, antibody detection is another test type to determine COVID-19 infection. This test can show whether a person is currently infected or has been infected. Unlike, RT-PCR, antibody type tests are currently not approved for use as a diagnostic tool but only for research. The antibody test has two process types, cassette-based and lab-based. The cassettebased assay includes either a lateral flow assay (LFA) or chemiluminescence immunoassay (CLIA) while the labbased has an enzyme linked immunoabsorbent assay (ELISA), microsphere immunoassay (MIA), etc. LFA, the most common cassette-based assay, takes 10-30 minutes to complete and examines the presence of antibodies in serum. ELISA, on the other hand, is the most common lab-based assay, takes 2-5 hours to complete, and provides quantification of antibodies. Lab-based tests have several advantages over cassette-based systems because they utilize sensitive laboratory instruments and controlled test environments. However, cassette-based tests have their own advantages as well, including ease, quick response times, and cost-efficiency $(24,25)$.

The principle behind LFA is simple: antigen-antibody binding affinity (26). Figure 3 explains the basic procedure of a LFA-based COVID-19 diagnostic test kit. First, fluid sample is applied to a sample pad. This then migrates to the conjugate release pad, which contains antigens for either SARS-CoV-2 or control antibodies. These antigens are conjugated to colored or fluorescent particles for indication. Once the fluid reaches the conjugate release pad, if present, IgG and IgM antibodies from the fluid bind to the SARS$\mathrm{CoV}-2$ antigen conjugates. Then, the fluid moves to the test line, which has antibodies for target detection. If the migrating fluid contains the target antibodies, color or fluorescence develops to indicate the results, as shown in Figure 3 (right). The control line is used to verify proper fluid flow and contains anti-rabbit IgG antigens to capture the rabbit $\mathrm{IgG}$ conjugate antibodies from the release pad. If the control line does not show positive, the results should not be trusted. The results of the LFA test kit should be analyzed as indicated from the supplier (16).

\section{Diagnostic kits widely used in the U.S.}

On January 31, 2020, the Secretary of Health and Human Services (HHS) declared a public health emergency recognizing the potential threat of SARS-CoV-2. The Federal Drug Administration (FDA) issued an emergency use authorization (EUA) to enable emergency use of the CDC 2019-nCoV Real-Time RT-PCR Diagnostic Panel, which was the first U.S. diagnostic kit. The FDA immediately issued a guidance policy specific to COVID-19 diagnostic kits on February 29, 2020 (27,28).

To be authorized for use by the FDA under EUA conditions, the performance of test kits must be verified (29). For molecular tests, analytical performance (limit of detection, reactivity/inclusivity results, specificity/ exclusivity, etc.) and clinical performance should be clearly stated. The performance of antibody tests can be defined with sensitivity (PPA) and specificity (NPA). Currently, all FDA EUA issued molecular tests have more than $95 \%$ accuracy above the limit of detection. Present antibody tests show around 90\% PPA and NPA (20). So far, more than $17,612,125$ tests have been conducted and approximately $9.8 \%$ of total tests have been confirmed positive for COVID-19 in the U.S. (5). As of June 1, 2020, the FDA has approved 86 COVID-19 diagnostic kits (Table 1) (29).

\section{Diagnostic kits widely used in South Korea}

On January 20, 2020, the same day that the U.S. reported its first COVID-19 case, South Korea confirmed their own first COVID-19 patient. Within 2 weeks, South Korea approved its first diagnostic kit, the PowerCheckTM2019$\mathrm{nCoV}$. In order to be authorized for use, COVID-19 diagnostic kits in South Korea must have defined limit of blank (LDB), limit of detection, limit of quantification (LoQ), strain reactivity, cross-reactivity, repeatability, crosscontamination, and clinical performance (30). As of June $1^{\text {st }}, 2020,6$ molecular type tests have been approved for domestic use (Table 2). All of the approved diagnostic test kits have more than $90 \%$ accuracy (31). So far, South Korea has conducted 921,391 tests, of which $1.2 \%$ have been confirmed to be positive for COVID-19 (5).

\section{Diagnostic kits widely used in China}

SARS-CoV-2 has caused a great concern for public health and governance. The WHO held a meeting on January 30, 2020 to declare the outbreak of coronavirus in China 

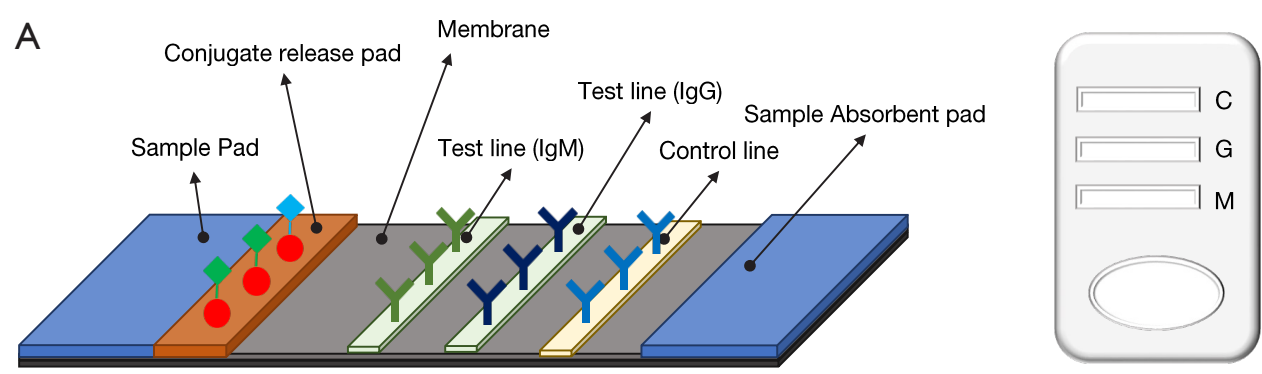

LFA Test kit
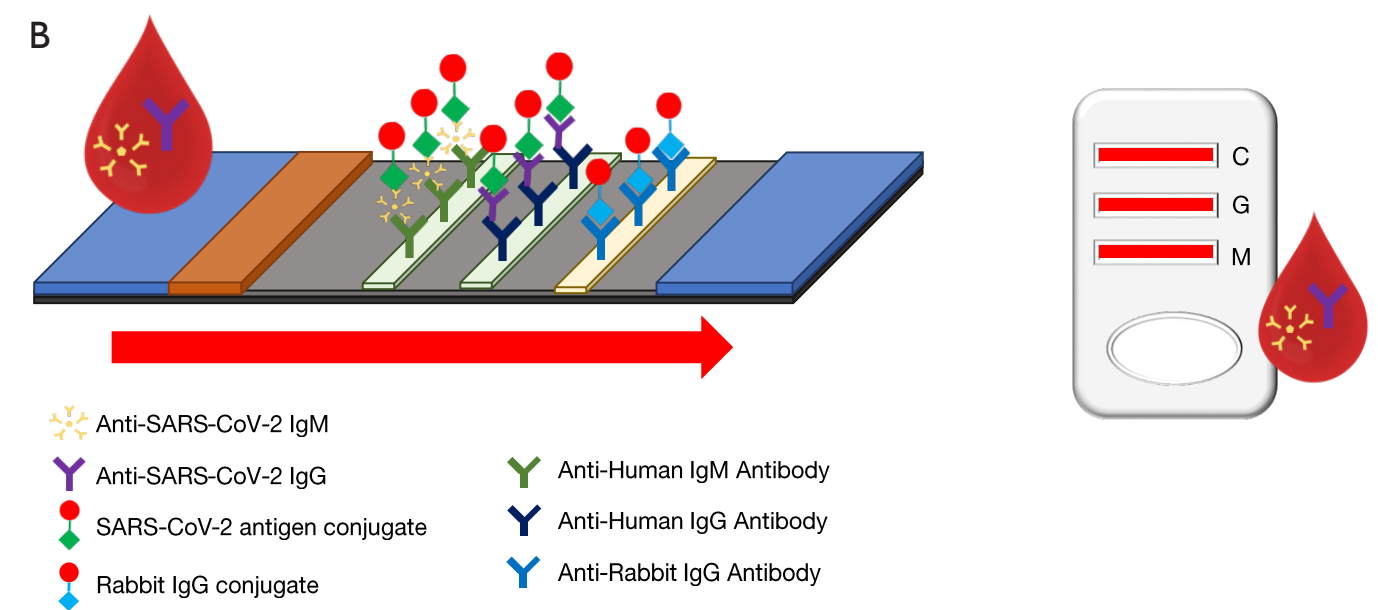

Figure 3 Example of an LFA-based COVID-19 diagnostic test (A) Inside structure of LFA-based COVID-19 diagnostic test Kit (left). Unused test kit result (right). The kit detects the antibodies (IgG, IgM) derived from COVID-19 in the sample. (B) Antigen-antibody binding affinity of test kit with COVID-19 Positive patient's sample (left). Test kit result of COVID-19 positive patient (right). LFA, lateral flow assay.

as a public health emergency of international concern. After the outbreak of the virus, the Chinese government issued a series of effective anti-epidemic measures, and the international community recognized that China has made great progress in effectively responding epidemics. As a result, there are many lessons to be learned from the experiences of epidemic control in China. For example, many Chinese medical and biotechnology companies immediately funneled resources into developing COVID-19 test kits. Initially, test results could be generated within 6 hours; however, now the shortest tests can be done within 15 minutes. This has been incredibly useful for screening, early diagnosis, treatment, and post-treatment analysis.

As of March 27, 2020, the National Medical Products Administration (NMPA), which is the Chinese governmental agency responsible for regulating drugs and medical devices, has approved 15 nucleic acid reagent test kits and 8 antibody reagent test kits. See Table 3 for details.

\section{Tracing person-to-person contact: current usage of smartphone applications}

COVID-19 is a respiratory illness, which makes it highly contagious. SARS-CoV-2 can be transferred from person to person mainly through respiratory droplets. One of the biggest challenges to slowing down the spread of COVID-19 is the prevalence of asymptomatic patients who are unaware that they are carriers. As a result, enforcing isolation of COVID-19 patients and recommending self-quarantine for those who may have been in contact for 14 days is required (32). Contact tracing plays an essential role in determining who should be isolated or quarantined (33). 
Table 1 List of U.S. COVID-19 diagnostic kits approved by the FDA under EUA

\begin{tabular}{|c|c|c|c|}
\hline No. & Product name & Company name & Instruction for use \\
\hline 2 & ID NOW COVID-19 (Near) & $\begin{array}{l}\text { Abbott Diagnostics } \\
\text { Scarborough, Inc. }\end{array}$ & https://www.fda.gov/media/136525/download \\
\hline 3 & SARS-CoV-2 IgG assay (CLIA) & Abbott Laboratories Inc. & https://www.fda.gov/media/137383/download \\
\hline 6 & $\begin{array}{l}\text { RealStar SARS-CoV02 RT-PCR Kits } \\
\text { U.S. (PCR) }\end{array}$ & Altona Diagnostics $\mathrm{GmbH}$ & https://www.fda.gov/media/137252/download \\
\hline 7 & Linea COVID-19 Assay Kit (PCR) & Applied DNA Sciences, Inc. & https://www.fda.gov/media/138059/download \\
\hline 11 & AvellinoCoV2 test (PCR) & Avellino Lab USA, Inc. & https://www.fda.gov/media/136453/download \\
\hline 12 & $\begin{array}{l}\text { BD SARS-CoV-2Reagents for BD MAX } \\
\text { System (PCR) }\end{array}$ & Becton, Dickinson \& Company & https://www.fda.gov/media/136816/download \\
\hline 13 & $\begin{array}{l}\text { BioGX SARS-CoV-2 Reagents for BD MAX } \\
\text { System (PCR) }\end{array}$ & Becton, Dickinson \& Company (BD) & https://www.fda.gov/media/136653/download \\
\hline 14 & $\begin{array}{l}\text { Real-Time Fluorescent RT-PCR Kit for } \\
\text { Detecting SARS-CoV-2 (PCR) }\end{array}$ & BGI Genomics Co. Ltd & https://www.fda.gov/media/136472/download \\
\hline 15 & $\begin{array}{l}\text { BioCore 2019-nCoV Real Time PCR } \\
\text { Kit (PCR) }\end{array}$ & BioCore Co., Ltd. & https://www.fda.gov/media/138290/download \\
\hline 21 & qSARS-CoV-2 IgG/lgM Rapid Test (LFA) & Cellex Inc. & https://www.fda.gov/media/136625/download \\
\hline 22 & $\begin{array}{l}\text { CDC 2019-nCoV Real-Time RT-PCR } \\
\text { Diagnostic Panel (CDC) (PCR) }\end{array}$ & $\begin{array}{l}\text { Centers for Disease Control and } \\
\text { Prevention's (CDC) }\end{array}$ & https://www.fda.gov/media/134922/download \\
\hline 23 & Xpert Xpress SARS-CoV-2 test (POC-PCR) & Cepheid & https://www.fda.gov/media/136314/download \\
\hline 24 & DPP COVID-19 IgM/lgG System (LFA) & Chembio Diagnostic System, Inc & https://www.fda.gov/media/136963/download \\
\hline 25 & $\begin{array}{l}\text { Logix Smart Coronavirus Disease } 2019 \\
\text { (COVID-19) Kit (PCR) }\end{array}$ & Co-Diagnostics, Inc. & https://www.fda.gov/media/136687/download \\
\hline 26 & Hymon SARS-CoV-2 Test Kit (PCR) & dba SpectronRx & https://www.fda.gov/media/138345/download \\
\hline 27 & QuantiVirus SARS-CoV-2 Test kit (PCR) & DiaCarta, Inc & https://www.fda.gov/media/136809/download \\
\hline 28 & LIAISON SARS-CoV-2 S1/S2 lgG & DiaSorin Inc. & https://www.fda.gov/media/137359/download \\
\hline 29 & Simplexa COVID-19 Direct assay (PCR) & DiaSorin Molecular LLC & https://www.fda.gov/media/136286/download \\
\hline 30 & Anti-SARS-CoV-2 ELISA (IgG) (ELISA) & EUROIMMUN US Inc. & https://www.fda.gov/media/137609/download \\
\hline
\end{tabular}

Table 1 (continued) 
Table 1 (continued)

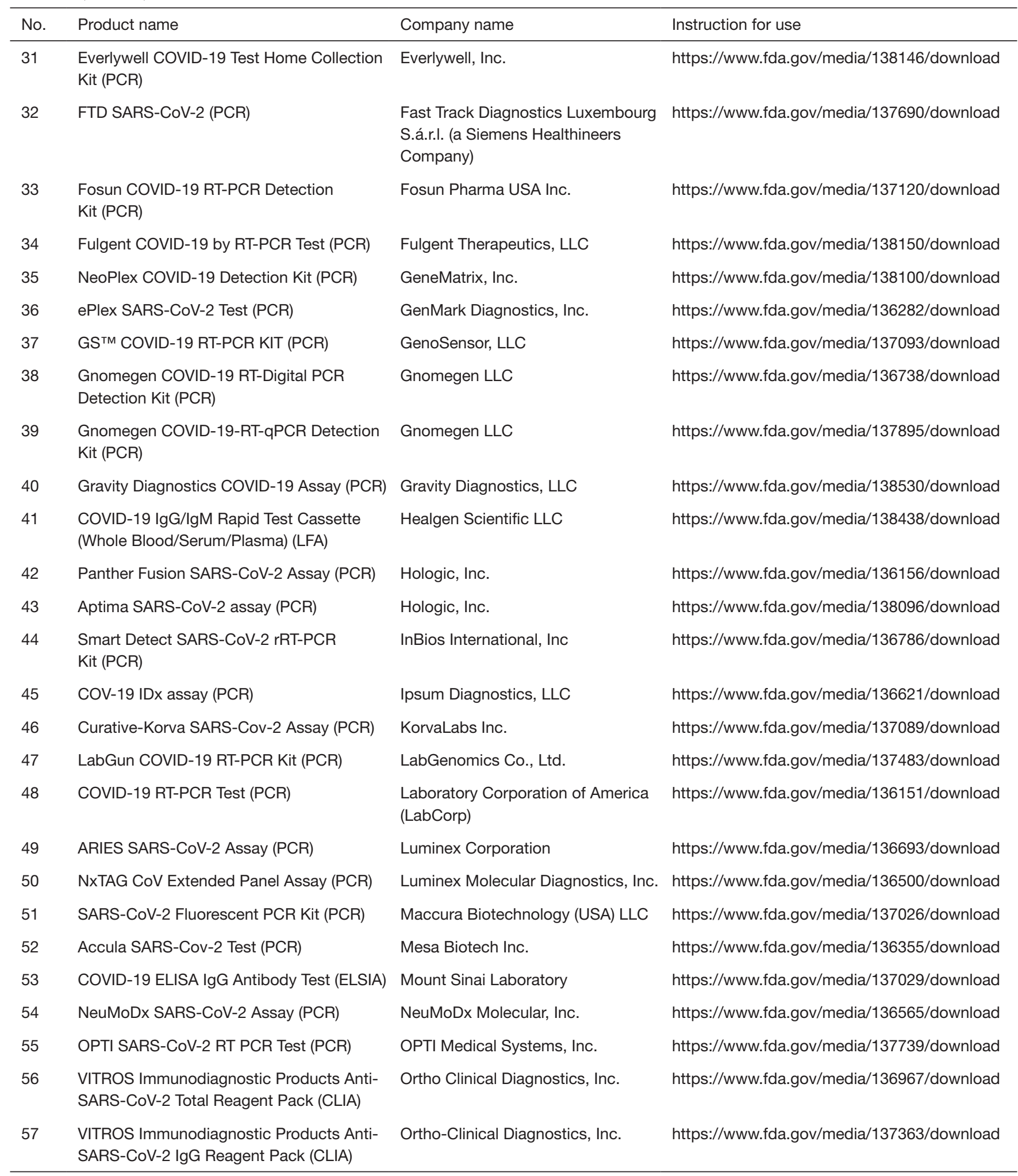

Table 1 (continued) 
Table 1 (continued)

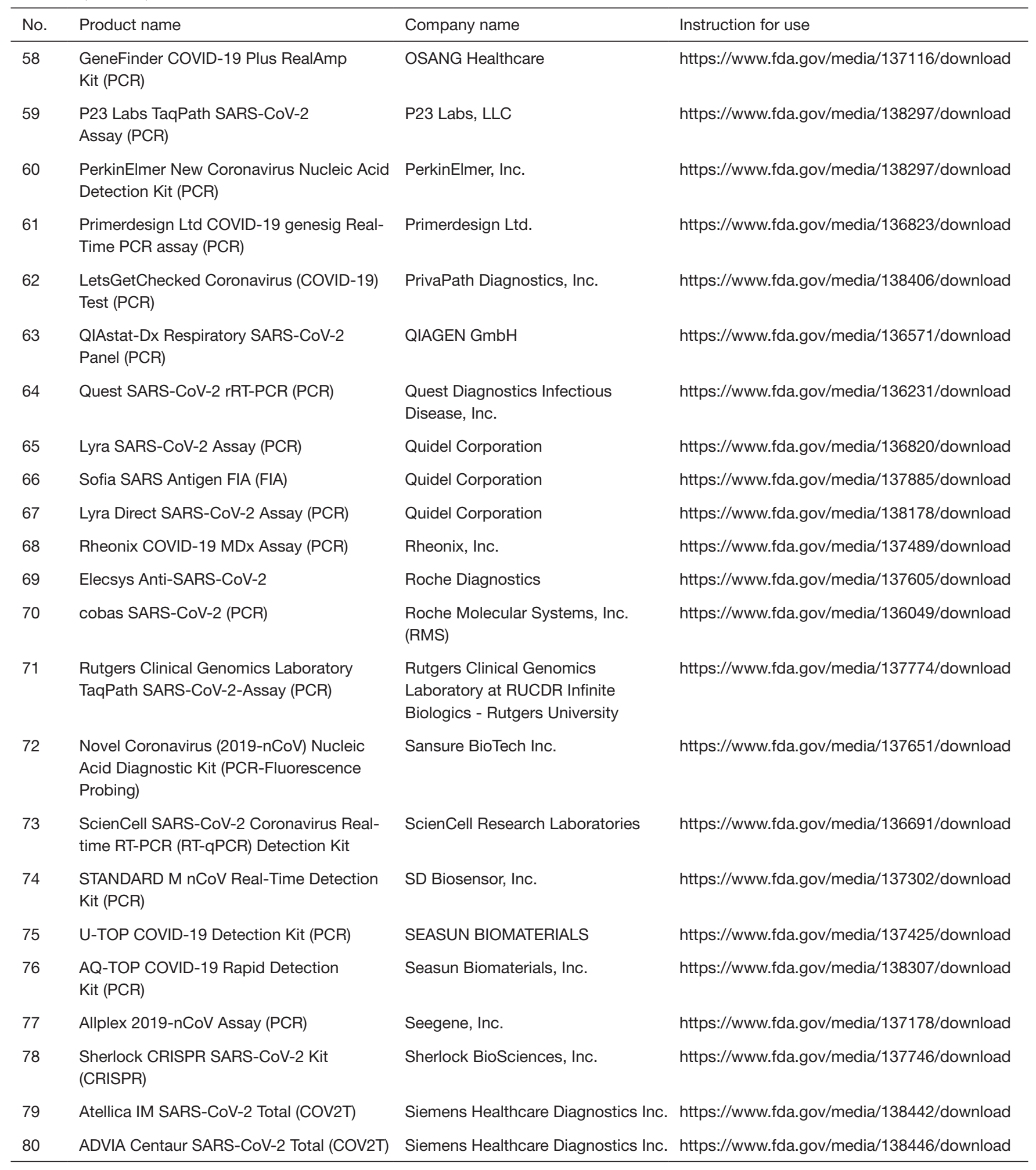

Table 1 (continued) 
Table 1 (continued)

\begin{tabular}{llll}
\hline No. & Product name & Company name & Instruction for use \\
\hline 81 & $\begin{array}{l}\text { DiaPlexQ Novel Coronavirus (2019-nCoV) } \\
\text { Detection Kit (PCR) }\end{array}$ & SolGent Co., Ltd. & https://www.fda.gov/media/138303/download \\
82 & TaqPath COVID-19 Combo Kit (PCR) & Thermo Fisher Scientific, Inc. & https://www.fda.gov/media/136112/download \\
83 & PhoenixDx 2019-CoV (PCR) & Trax Management Services Inc. & https://www.fda.gov/media/137153/download \\
84 & New York SARS-CoV Microsphere & Wadsworth Center, New York State & https://www.fda.gov/media/137541/download \\
& Immunoassay for Antibody Detection (MIA) & Department of Health & \\
85 & New York SARS-CoV-2 Real-time & Wadsworth Center, New York State & https://www.fda.gov/media/135847/download \\
& $\begin{array}{l}\text { Reverse Transcriptase (RT)-PCR Diagnostic } \\
\text { Panel (PCR) }\end{array}$ & Department of Public Health's (CDC) & \\
& Quick SARS-CoV-2rRT-PCR Kit (PCR) & Zymo Research Corporation & https://www.fda.gov/media/137780/download \\
\hline
\end{tabular}

FDA, Federal Drug Administration; EUA, emergency use authorization.

Table 2 List of COVID-19 diagnostic kits approved for use in South Korea

\begin{tabular}{lllll}
\hline No. & Product name & Company name & Company website \\
\hline 1 & PowerCheckTM2019-nCoV (PCR) & Kogene biotech & http://www.kogene.co.kr/eng/ & 02/04/2020 \\
2 & AllplexTM2019-nCoVAssay (PCR) & Seegene & http://www.seegene.com/ & 02/12/2020 \\
3 & DiaPlexQTMNovel Coronavirus (2019-nCov) Detection kit (PCR) & Solgent Co. & http://www.solgent.com/english & 02/27/2020 \\
4 & STANDARD M nCoV Detection kit (PCR) & SDBiosensor & http://sdbiosensor.com/xe/ & $02 / 27 / 2020$ \\
5 & Real-Q 2019-nCoV Detection Kit (PCR) & Biosewoom & http://www.biosewoom.com/ & $03 / 13 / 2020$ \\
6 & BioCore 2019-nCoV Real Time PCRKit (PCR) & Bio-core & http://www.bio-core.com/ & $05 / 11 / 2020$ \\
\hline
\end{tabular}

This enables public health officials to quickly identify people who may have had exposure to COVID-19 and allows them to act accordingly.

\section{South Korea's policy for tracing}

Realizing the importance of contact tracing, South Korea implemented a smart city platform for contact tracing on March 26, 2020. This same approach was not successfully applied to other Western countries due to potential privacy issues. This smart city platform is a state of the art "system of systems" that integrates multiple high technologies, including information and communications, big data, and artificial intelligence, to solve burdens for high quality life in many different fields.

Once a COVID-19-postive patient is identified, the screening center reports the case to the Korea Centers for Disease Control and Prevention (KCDC). The KCDC then registers the patient on a contact tracing system linked to the smart city data hub. Once the patient is registered, the system contacts the National Police Agency for the patient's information and requests to the Credit Finance Association (CREFIA). If the CREFIA approves, the hub requests the patient's epidemiological information from cellular service providers and credit card companies. Through this, the KCDC can collect all pertinent information regarding the patient within 10 minutes. The KCDC releases the information to the public after verification of the patient from the smart city data hub and alerts others who may have been in contact with the patient. People who receive an alert must be tested regardless of symptom manifestation. The patient information available to the public includes any public transportation that he or she took, locations visited, and time frames. This data is available for 14 days.

Meanwhile, in the U.S., once a COVID-19 patient is identified, trained public health staff manually conduct contact tracing by interrogating the patient directly. With the attained information, health officials then alert those 
Table 3 List of emergency NMPA-approved COVID-19 testing kits in China

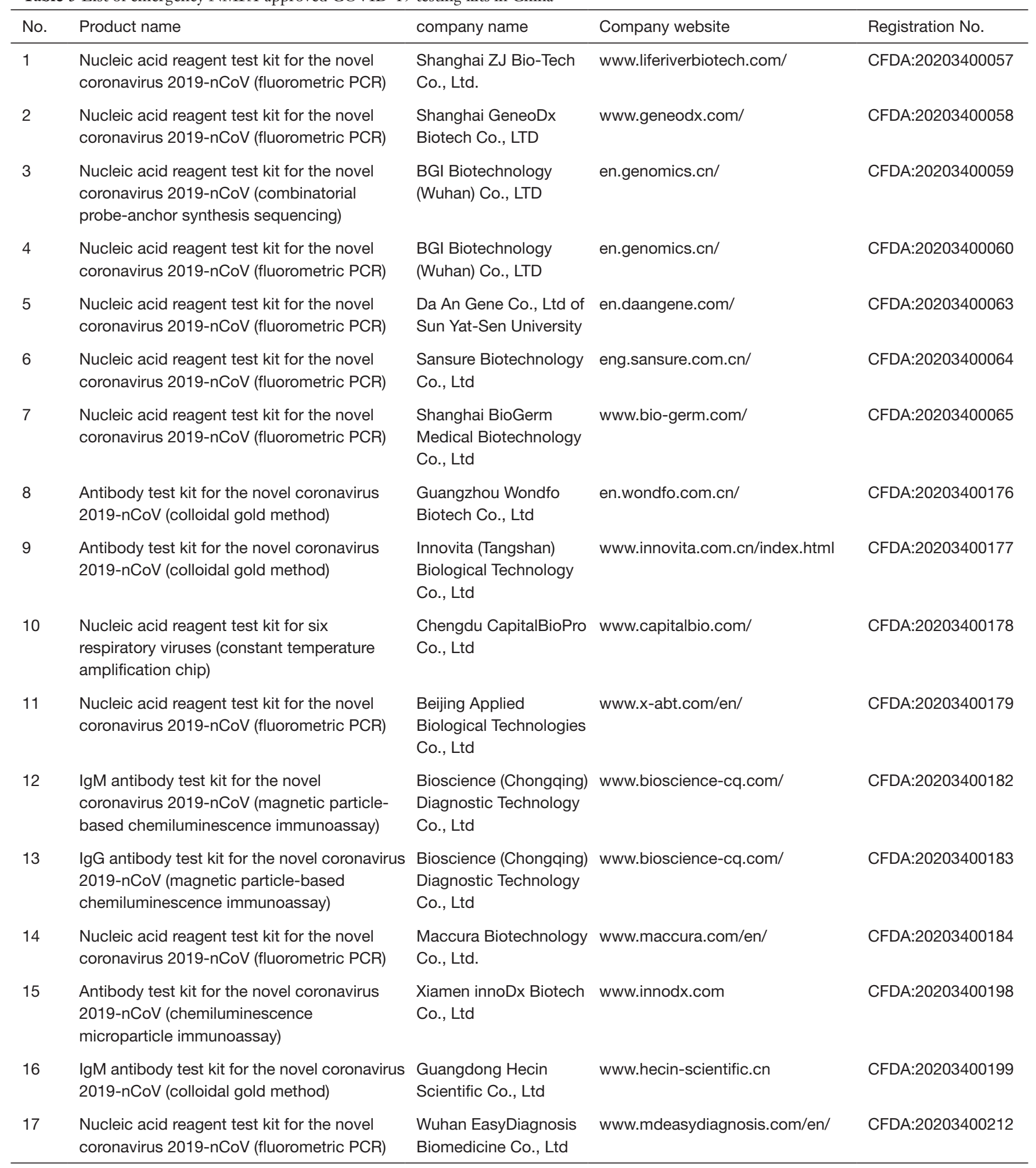

Table 3 (continued) 
Table 3 (continued)

\begin{tabular}{|c|c|c|c|c|}
\hline No. & Product name & company name & Company website & Registration No. \\
\hline 19 & $\begin{array}{l}\text { IgM/lgG antibody test kit for the novel } \\
\text { coronavirus 2019-nCoV (colloidal gold } \\
\text { method) }\end{array}$ & $\begin{array}{l}\text { Zhuhai Livzon } \\
\text { Diagnostics Co., Ltd }\end{array}$ & www.livzondiagnostics.com/en-us/ & CFDA:20203400240 \\
\hline 21 & $\begin{array}{l}\text { Nucleic acid reagent test kit for the novel } \\
\text { coronavirus 2019-nCoV (Hybrid capture } \\
\text { immunofluorescence assay) }\end{array}$ & $\begin{array}{l}\text { Anbio (Xiamen) } \\
\text { Biotechnology Co., Ltd }\end{array}$ & www.anbio.com/en/ & CFDA:20203400298 \\
\hline 23 & $\begin{array}{l}\text { Nucleic acid reagent test kit for the novel } \\
\text { coronavirus 2019-nCoV (RNA capture probe } \\
\text { method) }\end{array}$ & $\begin{array}{l}\text { Shanghai Rendu } \\
\text { Biotechnology Co., Ltd }\end{array}$ & www.rdbio.com/ & CFDA:20203400300 \\
\hline
\end{tabular}

NMPA, the National Medical Products Administration.

who may have had potential exposure. The substantial differences in contact tracing between the U.S. and South Korea arises from the levels of information disclosure and privacy.

\section{Smartphone applications for preventing the spread of COVID-19}

A multitude of researchers and companies are now striving to develop supplemental tools for preventing the spread of COVID-19. There has especially been a deluge of smartphone applications on the market due to its usefulness, affordability, and accessibility (Table 4). Smartphone applications derived from contact tracing or information sourcing has received particular attention $(34,35)$. As mentioned previously, there are noted differences in tracing or tracking between countries due to privacy laws and attitudes.

In the U.S., tracing applications function mainly to alert exposure to SARS-CoV-2. One such application is Healthy Together by Twenty Holding Inc. The applications use Bluetooth signals and GPS location data to collect a list of people that the user has had encounters with (per the user's consent). If the user meets other users within a certain range, the Bluetooth signal allows each user to share their encrypted serial number. GPS data is collected to understand transmission zones. If any of the users get diagnosed with COVID-19, other users who have encountered the patient will be alerted of the possible exposure with details such as the time and date. This mechanism can protect users' privacy while alerting others at risk.

Because the KCDC is already implementing a comprehensive tracing program, there are no applications with similar functionality in South Korea. Instead, there are other types of tracking applications on the market. The main function of these is alerting people when they are near COVID-19 patients using data attained from the KCDC. By informing users of potential risk, these applications can reduce infection rates. Additionally, the Korean Ministry of the Interior and Safety recently started operating an application called the Self-Quarantine Safety Protection App. This is a mandatory installation for anyone entering South Korea. It collects the users' personal information, symptoms, and GPS location in real-time and shares the data with the KCDC. Contact tracing applications are not the only informative utilities against spread. There are multiple applications that inform accurate and necessary 
Table 4 Smartphone applications used in South Korea and the United States

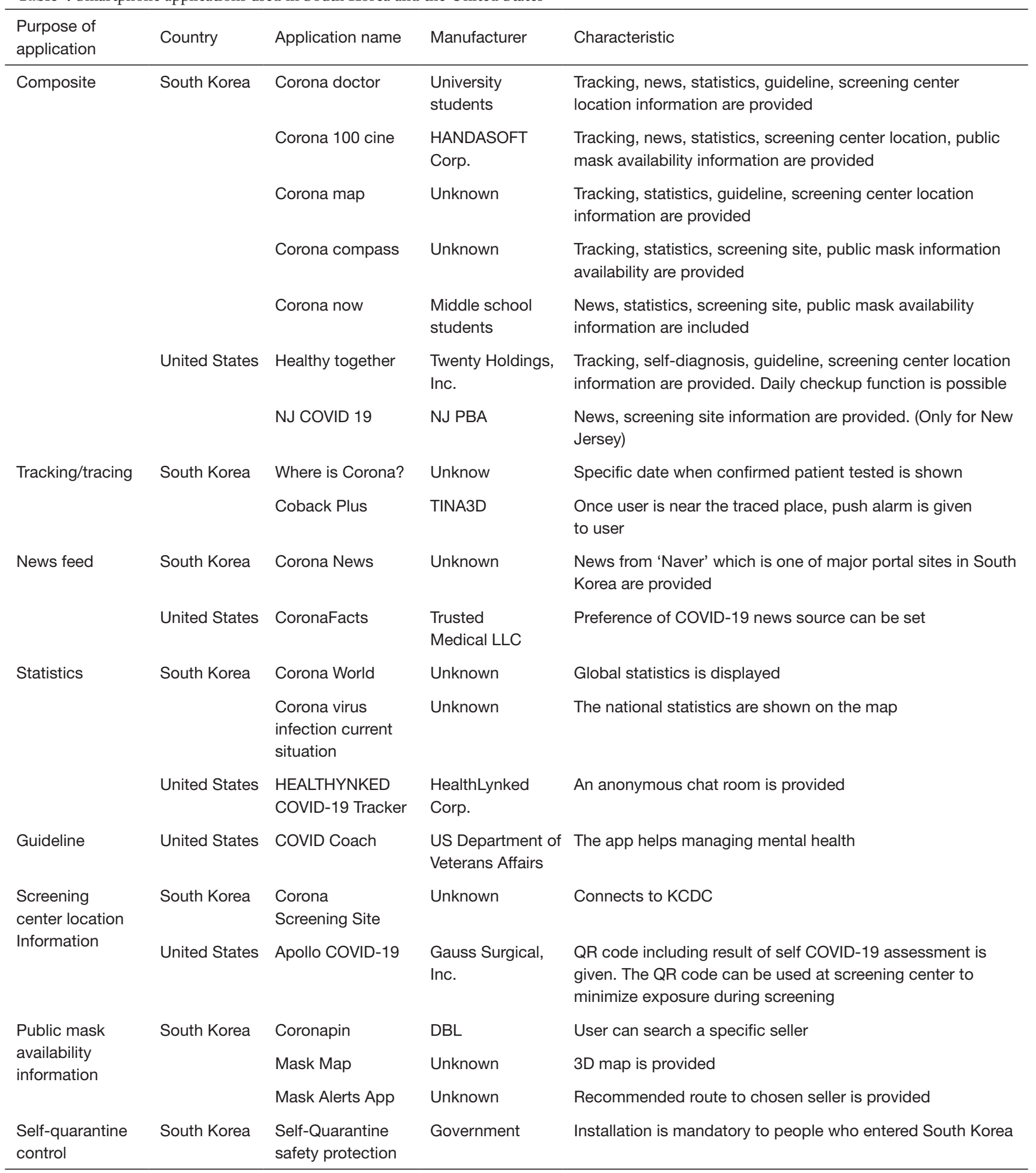

Table 4 (continued) 
Table 4 (continued)

\begin{tabular}{|c|c|c|c|c|}
\hline $\begin{array}{l}\text { Purpose of } \\
\text { application }\end{array}$ & Country & Application name & Manufacturer & Characteristic \\
\hline \multirow[t]{3}{*}{ Self-diagnosis } & South Korea & $\begin{array}{l}\text { Corona Self- } \\
\text { diagnosis }\end{array}$ & Unknown & Questions based on self-diagnosis for staff are given \\
\hline & \multirow[t]{2}{*}{ United States } & Apple COVID-19 & Apple | CDC & The application is available in 34 languages \\
\hline & & 1-Check COVID & $\begin{array}{l}\text { University of } \\
\text { Nebraska }\end{array}$ & User can share the result of self-diagnosis \\
\hline \multirow[t]{2}{*}{$\begin{array}{l}\text { Symptom } \\
\text { research }\end{array}$} & \multirow[t]{2}{*}{ United States } & $\begin{array}{l}\text { COVID Symptom } \\
\text { Study }\end{array}$ & $\begin{array}{l}\text { Zoe Global } \\
\text { Limited }\end{array}$ & Health advice is provided \\
\hline & & How We Feel & $\begin{array}{l}\text { The How We Feel } \\
\text { Project, Inc. }\end{array}$ & It tells user how many people have symptoms near the user \\
\hline
\end{tabular}

information to users, such as statistics, new guidelines, screening center locations, news updates, and face mask availability. For instance, in South Korea, there is a smartphone application for where face masks are available to purchase. This is specifically possible in South Korea because the government has allocated face masks to be sold only in assigned pharmacies.

\section{Prospectives/future directions}

When it comes to testing for COVID-19, most diagnostic tests take either a molecular or antibody approach. Within each of these, there subsets of tests that are ideal for different patients, time frames, and needs. As a result, it is essential that diagnostic test kits are utilized accordingly. For instance, mRNA-based testing kits are best utilized during the earlier stages of the infection while antibody tests are ideal for longer time frames after. These considerations must be made particularly for asymptomatic patients who may either have an active infection or recently fought off the virus. Contact tracing is another key element for preventing further spread of SARS-CoV-2. The South Korean government has taken an immensely precautious approach with much success; however, there are some issues with privacy that can arise. In the U.S., smartphone applications are not as widely popular and entail mostly on exposure alerts.

The COVID-19 pandemic has tested the preparedness and response of each nation. These lessons are critical for moving forward and are necessary to address for potential future public health events. Advancements in science and technology has made diagnostic testing readily available; however, the logistics, regulation, and distribution of such tests can be improved. Integration of smart technology in everyday life has also raised interesting prospects for future use in public health, but its tradeoff with privacy remains controversial. As nations continue onto the next steps of the pandemic, testing and tracing needs to evolve and adapt to meet changing demands as well.

\section{Acknowledgments}

We appreciate Dr. Heemin Rhee, a former FDA/CDER specialist and current President of Health Research International, for his scientific input on this manuscript.

Funding: This research was funded by National Institutes of Health (1U01DK103260, 1R01DK100974, U24 DK097154, NIH NCATS UCLA CTSI UL1TR000124), Department of Defense (W81XWH-15-1-0415 and W81XWH-19-1-0109), Centers for Disease Controls and Prevention (1U01DP006079), and the U.S.-Egypt Science and Technology Development Fund by the National Academies of Sciences, Engineering, and Medicine (all to J.K.). This research was also supported by the Samuel Oschin Comprehensive Cancer Institute (SOCCI) at Cedars-Sinai Medical Center through 2019 Lucy S. Gonda Award. This article is derived from the Subject Data funded in whole or part by National Academies of Sciences, Engineering, and Medicine (NAS) and The United States Agency for International Development (USAID). Any opinions, findings, conclusions, or recommendations expressed in this article are those of the authors alone, and do not necessarily reflect the views of USAID or NAS. 


\section{Footnote}

Reporting Checklist: The authors have completed the Narrative Review reporting checklist. Available at http:// dx.doi.org/10.21037/tau-20-1042

Conflicts of Interest: All authors have completed the ICMJE uniform disclosure form (available at http://dx.doi. org/10.21037/tau-20-1042). The authors have no conflicts of interest to declare.

Ethical Statement: The authors are accountable for all aspects of the work in ensuring that questions related to the accuracy or integrity of any part of the work are appropriately investigated and resolved.

Open Access Statement: This is an Open Access article distributed in accordance with the Creative Commons Attribution-NonCommercial-NoDerivs 4.0 International License (CC BY-NC-ND 4.0), which permits the noncommercial replication and distribution of the article with the strict proviso that no changes or edits are made and the original work is properly cited (including links to both the formal publication through the relevant DOI and the license). See: https://creativecommons.org/licenses/by-nc-nd/4.0/.

\section{References}

1. Mortality analyses. Available online: https://coronavirus. jhu.edu/data/mortality

2. Mizumoto K, Kagaya K, Zarebski A, et al. Estimating the asymptomatic proportion of coronavirus disease 2019 (COVID-19) cases on board the Diamond Princess cruise ship, Yokohama, Japan, 2020. Euro Surveill 2020;25:2000180.

3. Holshue ML, DeBolt C, Lindquist S, et al. First Case of 2019 Novel Coronavirus in the United States. N Engl J Med 2020;382:929-36.

4. US coronavirus cases surge tenfold in a week to 50,000, global infections soar past 400,000. Available online: https://www.cnbc.com/2020/03/24/global-coronaviruscases-cross-400000-doubling-in-a-week-as-pandemicaccelerates.html

5. Available online: https://ourworldindata.org/coronavirus.

6. Xu S, Li Y. Beware of the second wave of COVID-19. Lancet 2020;395:1321-2.

7. Chabner BA. Taking the Longer View of COVID-19. Oncologist 2020;25:455-7.
8. Weinstein E, Ragazzoni L, Burkle F, et al. Delayed Primary and Specialty Care: The Coronavirus Disease-2019 Pandemic Second Wave. Disaster Med Public Health Prep 2020;14:e19-21.

9. Qazi A, Qazi J, Naseer K, et al. Analyzing situational awareness through public opinion to predict adoption of social distancing amid pandemic COVID-19. J Med Virol 2020;92:849-55.

10. Kandeel M, Ibrahim A, Fayez M, et al. From SARS and MERS CoVs to SARS-CoV-2: Moving toward more biased codon usage in viral structural and nonstructural genes. J Med Virol 2020;92:660-6.

11. Kasibhatla SM, Kinikar M, Limaye S, et al. Understanding evolution of SARS-CoV-2: A perspective from analysis of genetic diversity of RdRp gene. J Med Virol 2020;92:1932-7.

12. Liu L, Liu W, Zheng Y, et al. A preliminary study on serological assay for severe acute respiratory syndrome coronavirus 2 (SARS-CoV-2) in 238 admitted hospital patients. Microbes Infect 2020;22:206-11.

13. Zou L, Ruan F, Huang M, et al. SARS-CoV-2 Viral Load in Upper Respiratory Specimens of Infected Patients. N Engl J Med 2020;382:1177-9.

14. Kim JY, Ko JH, Kim Y, et al. Viral Load Kinetics of SARSCoV-2 Infection in First Two Patients in Korea. J Korean Med Sci 2020;35:e86.

15. Jacofsky D, Jacofsky EM, Jacofsky M. Understanding Antibody Testing for COVID-19. J Arthroplasty 2020;35:S74-81.

16. Li Z, Yi Y, Luo X, et al. Development and clinical application of a rapid IgM-IgG combined antibody test for SARS-CoV-2 infection diagnosis. J Med Virol 2020;92:1518-24.

17. Kuypers J, Wright N, Ferrenberg J, et al. Comparison of real-time PCR assays with fluorescent-antibody assays for diagnosis of respiratory virus infections in children. J Clin Microbiol 2006;44:2382-8.

18. Vinh DB, Zhao X, Kiong KL, et al. Overview of COVID-19 testing and implications for otolaryngologists. Head Neck 2020;42:1629-33.

19. Xie J, Ding C, Li J, et al. Characteristics of patients with coronavirus disease (COVID-19) confirmed using an IgMIgG antibody test. J Med Virol 2020;92:2004-10.

20. Interim Guidelines for Collecting, Handling, and Testing Clinical Specimens for COVID-19. Available online: https://www.cdc.gov/coronavirus/2019-ncov/lab/ guidelines-clinical-specimens.html 
21. Tahamtan A, Ardebili A. Real-time RT-PCR in COVID-19 detection: issues affecting the results. Expert Rev Mol Diagn 2020;20:453-4.

22. Bustin SA. Quantification of mRNA using real-time reverse transcription PCR (RT-PCR): trends and problems. J Mol Endocrinol 2002;29:23-39.

23. Schrick L, Nitsche A. Pitfalls in PCR troubleshooting: Expect the unexpected? Biomol Detect Quantif 2016;6:1-3.

24. Gwyn S, Cooley G, Goodhew B, et al. Comparison of Platforms for Testing Antibody Responses against the Chlamydia trachomatis Antigen Pgp3. Am J Trop Med Hyg 2017;97:1662-8.

25. Izzo MM, Kirkland PD, Gu X, et al. Comparison of three diagnostic techniques for detection of rotavirus and coronavirus in calf faeces in Australia. Aust Vet J 2012;90:122-9.

26. Elif BB MK. Lateral flow assays: Principles, designs and labels. TrAC Trends in Analytical Chemistry 2016;82:286-306.

27. FDA Takes Significant Step in Coronavirus Response Efforts, Issues Emergency Use Authorization for the First 2019 Novel Coronavirus Diagnostic. Available online: https://www.fda.gov/news-events/press-announcements/ fda-takes-significant-step-coronavirus-response-effortsissues-emergency-use-authorization-first

28. Declaration Under the Public Readiness and Emergency

Cite this article as: Park H, Jin P, Jung S, Kim J. Quick overview of diagnostic kits and smartphone apps for urologists during the COVID-19 pandemic: a narrative review. Transl Androl Urol 2021;10(2):939-953. doi: 10.21037/tau-20-1042
Preparedness Act for Medical Countermeasures Against COVID-19. Available online: https://www.federalregister. gov/documents/2020/03/17/2020-05484/declarationunder-the-public-readiness-and-emergency-preparednessact-for-medical-countermeasures

29. Emergency Use Authorizations for Medical Devices. Available online: https://www.fda.gov/medical-devices/ emergency-situations-medical-devices/emergency-use-aut horizations\#covid19ivdTemplates

30. Public Official's Guideline. Complainant's Guide. Available online: https://www.nifds.go.kr/brd/m_15/view. do? seq $=12842$

31. International Risk Information. Available online: https:// www.mfds.go.kr/eng/brd/m_60/view.do?seq=74424

32. Abeler J, Backer M, Buermeyer U, et al. COVID-19 Contact Tracing and Data Protection Can Go Together. JMIR Mhealth Uhealth 2020;8:e19359.

33. Rubin R. Building an "Army of Disease Detectives" to Trace COVID-19 Contacts. JAMA 2020;323:2357-60.

34. Iyengar K, Upadhyaya GK, Vaishya R, et al. COVID-19 and applications of smartphone technology in the current pandemic. Diabetes Metab Syndr 2020;14:733-7.

35. Vokinger KN, Nittas V, Witt CM, et al. Digital health and the COVID-19 epidemic: an assessment framework for apps from an epidemiological and legal perspective. Swiss Med Wkly 2020;150:w20282. 